\title{
Uso de microfiltração para melhoria da qualidade e extensão da vida de prateleira de leite pasteurizado
}

Use of microfiltration to improve the quality and extend the shelf life of pasteurized milk

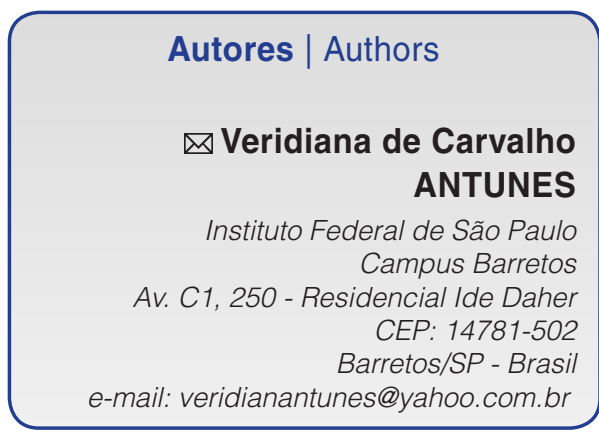

Autor Correspondente / Corresponding Author

Recebido / Received: 19/11/2013 Aprovado / Approved: 17/03/2014

Publicado / Published: mar./2014

\section{Resumo}

A microfiltração é uma das tecnologias utilizadas para melhorar a qualidade do leite fluido. O objetivo dessa revisão é abordar o uso da microfiltração do leite para estender sua vida de prateleira. A importância da qualidade do leite cru (microorganismos contaminantes e enzimas naturais do leite, provenientes das células somáticas ou do crescimento dos microrganismos psicrotróficos) e as condições de estocagem do leite cru (refrigeração), que são decisivas para a qualidade e vida de prateleira do leite pasteurizado, também serão discutidas. São mencionados os progressos já obtidos e em desenvolvimento da tecnologia de microfiltração para a extensão da vida de prateleira do leite pasteurizado e a importância da microfiltração para manter as características nutricionais do leite. Ainda serão descritos os problemas associados com incrustações da membrana que afetam o seu desempenho.

Palavras-chave: microfiltração; refrigeração do leite.

\section{Summary}

Microfiltration is one of the technologies used to improve the quality of liquid milk. The objective of this review was to consider the use of microfiltration to extend the shelf life of milk. The importance of the quality of the raw milk (contaminating microorganisms and enzymes: natural to the milk, from somatic cells or the growth of psychrotrophic microorganisms) and the storage conditions of the raw milk (refrigeration), which are decisive for the quality and shelf life of the pasteurized milk, were also discussed. Progress already made and under development for the use of microfiltration technology to extend the shelf life of pasteurized milk and the importance of microfiltration to maintain the nutritional characteristics of milk were mentioned. Problems associated with fouling of the membrane that affect its performance were also described.

Key words: microfiltration; refrigerated milk. 


\section{Introdução}

A extensão da vida de prateleira do leite pasteurizado (LP), mantendo as características físicoquímicas, microbiológicas e sensoriais, é um desafio e uma necessidade para a indústria de laticínios. Além da redução dos custos de produção e melhoria da logística de distribuição, o aumento da vida de prateleira do leite pasteurizado atende à busca do consumidor por alimentos mais naturais, seguros, convenientes e sem os defeitos sensoriais normalmente associados com tratamentos térmicos intensos.

No Brasil, existem basicamente dois tipos de leite fluido de consumo, o leite pasteurizado e o leite longa vida ou UHT (ultra high temperature). Nos últimos anos, houve uma diminuição no consumo de leite pasteurizado e crescimento considerável no consumo de leite UHT (EMBRAPA, 2013), que pode ser armazenado à temperatura ambiente. No Brasil, o leite pasteurizado refrigerado, de acordo com os produtos do mercado, tem uma vida de prateleira de 3 a 8 dias, e o leite UHT de 2 a 6 meses. As alterações causadas por bactérias deterioradoras e a produção de enzimas por essas bactérias são os principais fatores que limitam a extensão da vida de prateleira do leite pasteurizado tradicional, ou seja, somente com uso de tratamento térmico ( $\left.72-75^{\circ} \mathrm{C} / 15-20 \mathrm{~s}\right)$. Além disso, a ocorrência de mastite nos animais e as condições de armazenamento refrigerado de leite no Brasil podem favorecer a alta produção de enzimas que diminuem a qualidade do leite cru, abreviando o tempo de vida de prateleira do leite pasteurizado. Já no caso do leite UHT, apesar do tratamento térmico eliminar praticamente todos os microrganismos, garantindo uma longa vida de prateleira, ele confere um sabor de cozido, que pode ser indesejável para uma parcela dos consumidores.

Uma alternativa para a produção de um leite de vida de prateleira estendida com características sensoriais similares às do leite pasteurizado seria a aplicação da microfiltração (MF) antes da pasteurização (MAUBOIS, 2002; LORENZEN et al., 2011). A microfiltração é uma tecnologia de membrana, não térmica, que reduz a carga microbiana do leite.

No presente artigo, a importância da qualidade do leite cru (a ação da plasmina, enzimas associadas à mastite e aquelas produzidas por microorganismos psicrotróficos) e o efeito do armazenamento refrigerado são revisados. O trabalho aborda o uso de microfiltração como tecnologia complementar para melhorar a qualidade do leite fluido, descrevendo os problemas associados com incrustações da membrana, bem como os progressos já obtidos e em desenvolvimento dessa tecnologia para a extensão da vida de prateleira do leite pasteurizado.

\section{Fatores que afetam a qualidade e vida de prateleira do leite}

\subsection{Qualidade do leite cru}

Entende-se por leite, sem outra especificação, o produto oriundo da ordenha completa, ininterrupta, e em condições de higiene, de vacas sadias, bem alimentadas e descansadas. Sendo o leite denominado de cru quando não passou por nenhum tratamento térmico.

O leite é um meio adequado para o desenvolvimento de vários tipos de microrganismos devido a sua composição rica em carboidratos, proteínas e gorduras combinados com o seu $\mathrm{pH}$ próximo da neutralidade (HAYES e BOOR, 2001).

Para a produção de leite de boa qualidade, são necessários diversos cuidados que se iniciam com a sanidade dos animais (incluindo melhoramento genético, bom manejo nutricional e controle sanitário) e boas práticas de ordenha (higienização dos utensílios/ equipamentos e do manipulador).

Contagens elevadas de microrganismos no leite cru evidenciam a existência de falhas nos procedimentos de manipulação, higienização e sanidade do animal, podendo comprometer a qualidade e diminuir a vida de prateleira do produto final (NÖRNBERG et al., 2009).

A deterioração microbiana é o principal fator limitante para a extensão da vida de prateleira do leite pasteurizado (BOOR, 2001). Portanto, a extensão da vida de prateleira do leite pasteurizado dependerá fundamentalmente da qualidade do leite cru, ou seja, da contagem inicial dos microrganismos, do tipo de bactérias presentes (SCHMIDT et al., 2012), do número de células somáticas e das condições de armazenamento a que o leite cru é submetido (BARBANO et al., 2006). Além disso, a presença de enzimas termorresistentes (proteases e lipases) produzidas por microrganismos psicrotróficos promove o desenvolvimento de sabores indesejáveis, limitando ainda mais a vida de prateleira do leite pasteurizado (FROMM e BOOR, 2004).

\subsection{Qualidade do leite cru refrigerado}

Os Regulamentos Técnicos da Instrução Normativa (IN) 51 (BRASIL, 2002) e 62 (BRASIL, 2011), que tornam obrigatória a refrigeração do leite cru na propriedade e sua coleta e transporte refrigerado em até 48 horas após a ordenha, representam um grande avanço para a melhoria da sua qualidade. Essa medida também resultou na alteração do perfil de microrganismos no leite, diminuindo os mesófilos e aumentando os psicrotróficos, que são microrganismos que crescem à temperatura de refrigeração, independentemente da sua temperatura ótima de crescimento (SANTOS et al., 2010). 
Os microrganismos psicrotróficos presentes no leite cru são bactérias Gram-negativas, sendo o genêro Pseudomonas o mais comumente encontrado em leite (COUSIN, 1982; SØRHAUG e STEPANIAK, 1997; DE JONGHE et al., 2011). O gênero Bacillus também merece destaque por possuir microrganismos formadores de esporos, como o Bacillus sporothermodurans, e por serem resistentes aos tratamentos térmicos aplicados ao leite, como o Bacillus stearothermophilus (SØRHAUG e STEPANIAK, 1997; CHEN et al., 2003).

É recomendável que a refrigeração do leite seja realizada a temperaturas menores que $5^{\circ} \mathrm{C}$ (COUSIN, 1982; HOFFMANN et al., 2006). Entretanto, a legislação brasileira permite que o leite seja refrigerado na fazenda a $7{ }^{\circ} \mathrm{C}$ e entregue no laticínio a $10^{\circ} \mathrm{C}$. Além disso, a legislação também permite que o leite cru, refrigerado em tanques de expansão comunitários, atinja temperaturas de até $10{ }^{\circ} \mathrm{C}$, nem sempre mantida durante o tempo de armazenamento. Depois do período de refrigeração na fazenda, é comum que o leite cru seja transportado para o entreposto ou direto para a usina beneficiadora, na qual ainda fica estocado por horas ou dias nos silos, antes de ser processado. O leite cru pode ainda ser comercializado entre diferentes indústrias de beneficiamento (mercado spot), aumentando o tempo de armazenamento antes do processamento (VIANA, 2010).

A estocagem refrigerada do leite cru por longos períodos de tempo afeta negativamente a qualidade do leite pasteurizado devido ao desenvolvimento dos microrganismos psicrotróficos (NÖRNBERG et al., 2010) que, apesar de serem destruídos na pasteurização, produzem lipases e proteases termorresistentes (COUSIN, 1982; CHEN et al., 2003). Defeitos de sabor e textura causados pela ação dessas enzimas são perceptíveis quando a população de psicrotróficos atinge contagens iguais ou superiores a $10^{6} \mathrm{UFC} / \mathrm{ml}$ (COUSIN, 1982; NÖRNBERG et al., 2009). O problema gerado pela estocagem inadequada e, consequentemente, o favorecimento do crescimento dos microrganismos psicrotróficos e de suas enzimas termorresistentes é ainda mais grave, pois muitos produtores não seguem o recomendado na legislação.

A relevância do binômio tempo/temperatura de refrigeração no crescimento dos microrganismos psicrotróficos já foi objeto de diversos estudos (HARYANI et al., 2003; LORENZETTI, 2006; SANVIDO, 2007; SANTOS et al., 2009; IZIDORO et al., 2010; LISITA, 2010).

Santos et al. (2009) observaram que apenas $38,24 \%$ das amostras foram coletadas dentro do prazo previsto pela legislação, que é de no máximo 48 horas, e $61,76 \%$ das amostras foram coletadas com até 216 horas de estocagem, que correspondem a 9 dias. Além disso, $11,76 \%$ das amostras também estavam com temperaturas acima do recomendado e foram detectadas diferenças entre a temperatura aferida com o termômetro e a lida no termostato do tanque de expansão, no momento da coleta.

A contagem de psicrotróficos, a produção de proteases e a proteólise (degradação/quebra das proteínas) foram avaliadas em leite cru estocado a 2, 4 e $7{ }^{\circ} \mathrm{C}$ por 10 dias. O leite cru estocado a $2{ }^{\circ} \mathrm{C}$ demorou 9 dias para atingir uma população de psicrotróficos de $10^{7} \mathrm{UFC} / \mathrm{mL}$, porém, quando estocado a $4^{\circ} \mathrm{C}$, a mesma contagem foi atingida em 7 dias e, na temperatura de $7^{\circ} \mathrm{C}$, em apenas 4 dias de armazenamento. O tempo mínimo para a detecção de proteólise também variou em função da temperatura de estocagem, sendo de 6, 4 e 2 dias quando estocado em 2, 4 e $7^{\circ} \mathrm{C}$, respectivamente (HARYANI et al., 2003). Viana (2010), do mesmo modo, observou que, quando o leite foi estocado a $4{ }^{\circ} \mathrm{C}$, demorou 5 dias para atingir uma população de $10^{6} \mathrm{UFC} / \mathrm{mL}$ de microrganismos psicrotróficos e, de 3-4 dias, quando estocado a $7^{\circ} \mathrm{C}$.

Quando o leite cru foi armazenado a $5{ }^{\circ} \mathrm{C}$ durante 4 e 7 dias, Sanvido (2007) verificou um aumento significativo de todos os microrganismos analisados (mesófilos, psicrotróficos, Pseudomonas spp., termodúricos e esporos) e da proteólise. A contagem inicial de microrganismos totais aumentou de $7,4 \times 10^{3}$ para $6,1 \times$ $10^{6}$ e 1,83 x 108 UFC/mL, respectivamente, após 4 e 7 dias de armazenamento refrigerado. Nos mesmos períodos, a contagem de psicrotróficos passou da ordem de $10^{3}$ para $10^{6}$ e $10^{7} \mathrm{UFC} / \mathrm{mL}$.

O aumento do número de psicrotróficos com o tempo e temperatura de resfriamento também foi observado em outro trabalho (IZIDORO et al., 2010), no qual o leite cru foi armazenado a 4,8 e $12^{\circ} \mathrm{C}$ por 12,24 e 48 h. Leite cru com contagem inicial de psicrotróficos menor que $4 \mathrm{log}$ UFC/mL e estocado a 4 e $8{ }^{\circ} \mathrm{C}$ por 48 h apresentou um aumento de, no máximo, 2 ciclos logarítmicos. No entanto, quando as contagens iniciais foram maiores que $4 \mathrm{log} U F C / m L$, as contagens finais de psicrotróficos foram superiores a 6 log UFC/mL, independentemente da temperatura de estocagem.

Lorenzetti (2006) mostrou o efeito do tempo de estocagem refrigerada do leite cru no desenvolvimento de microrganismos psicrotróficos. O leite que passou pelo entreposto antes de ser entregue na indústria, ou seja, mais de 72 horas de estocagem refrigerada, apresentou contagens de psicrotróficos muito elevadas na indústria $\left(9,8 \times 10^{8} \mathrm{UFC} / \mathrm{mL}\right)$, mesmo sendo estocado em temperatura média de $5,4^{\circ} \mathrm{C}$. Por outro lado, o leite entregue entre 24 e 48 horas após a ordenha atingiu contagens de 1,5 × $10^{6}$ UFC/mL, o que evidencia a necessidade de minimizar o tempo de estocagem refrigerada do leite. A importância da redução do tempo de estocagem do leite também foi demonstrada por Santos et al. (2009), que observaram 
que a contagem de microrganismos psicrotróficos no leite cru refrigerado $\left(5^{\circ} \mathrm{C}\right)$ aumentou de 3,0 log UFC/ $\mathrm{mL}$, após $24 \mathrm{~h}$ de armazenamento, para 4,9 log UFC/ ML, após $96 \mathrm{~h}$, atingindo 6,5 log UFC/mL após $216 \mathrm{~h}$ de armazenamento a $5^{\circ} \mathrm{C}$.

A estocagem refrigerada ineficiente do leite cru também pode afetar a qualidade do produto final. Leite UHT produzido com leite cru, previamente armazenado a $10^{\circ} \mathrm{C}$, apresentou maior extensão de proteólise e lipólise, com diminuição da relação caseína/proteína e aumento do teor de ácidos graxos livres ao longo do tempo de estocagem, quando comparado ao leite UHT originado de leite cru armazenado a 3 e $7^{\circ} \mathrm{C}$ por 3 dias (LISITA, 2010).

A ocorrência de proteólise no leite pode ser resultado da ação de enzimas proteolíticas responsáveis por diferentes alterações físico-químicas como a plasmina, as enzimas associadas à mastite e as enzimas termorresistentes dos psicrotróficos. Segundo Santos et al. (2003), no leite de boa qualidade microbiológica, a proteólise ocorrida é devida às proteases endógenas do leite, das quais a mais importante é a plasmina. Condições não adequadas de refrigeração do leite cru resultam em grande número de microrganismos psicrotróficos e produção de proteases termorresistentes. A proteólise também pode ser causada pelas enzimas das células somáticas, principalmente se a contagem destas no leite estiver alta (FERNANDES et al., 2008).

\subsection{Plasmina}

A proteólise do leite pode ser atribuída à plasmina e seu precursor inativo, o plasminogênio.

A plasmina é uma protease, com pH ótimo de 7,4-7,5, que degrada $\beta, \alpha_{\mathrm{s} 1}$ e $\alpha_{\mathrm{s} 2}$-caseínas, sendo a $\beta$-caseína a mais susceptível (HACHANA et al., 2010). 0 acúmulo de peptídeos hidrofóbicos, geralmente oriundos da degradação da $\beta$-caseína, resulta no desenvolvimento de gosto amargo em produtos lácteos (CHAVAN et al., 2011).

A pasteurização a $72{ }^{\circ} \mathrm{C}$ por 15 segundos reduz a atividade da plasmina entre $10 \%$ e $17 \%$, porém esta enzima pode estar presente mesmo após o processamento do leite em temperatura ultra-alta (140 ${ }^{\circ} \mathrm{C}$ por 3 segundos). O tratamento térmico pode também inativar os inibidores de ativadores de plasminogênio, aumentando dessa forma o teor de plasmina em leite pasteurizado (PRADO et al., 2007).

A refrigeração é outro fator que pode afetar os mecanismos de autólise e ativação do plasminogênio e, portanto, interferir na atividade da plasmina durante a estocagem refrigerada do leite cru. Crudden et al. (2005) observaram maior autólise da plasmina durante a estocagem do leite a $5{ }^{\circ} \mathrm{C}$ do que a 20 e $37^{\circ} \mathrm{C}$, o que pode ser atribuído à ocorrência de menor ativação do plasminogênio a baixas temperaturas. Os autores mostraram que os mecanismos que mais afetaram a ação hidrolítica da plasmina no leite foram a maior autólise a $5{ }^{\circ} \mathrm{C}$, em comparação com 20 e $37^{\circ} \mathrm{C}$ e a ativação do plasminogênio a $37^{\circ} \mathrm{C}$.

Em leite cru com baixa contagem de microrganismos, a proteólise ocorre principalmente pela ação da plasmina e, em leite com contagens superiores a $10^{6}$ UFC/ $\mathrm{mL}$, predomina a ação das proteases microbianas. Guinot-Thomas et al. (1995) mostraram que a atividade proteolítica das proteases microbianas foi mais importante que a da plasmina quando a população microbiana atingiu $10^{6}-10^{7} \mathrm{UFC} / \mathrm{mL}$ após armazenamento do leite cru a $4{ }^{\circ} \mathrm{C} / 4$ dias. No entanto, em leite de alta qualidade microbiológica (contagem menor que $10^{3} \mathrm{UFC} / \mathrm{mL}$ ), a atividade proteolítica observada após estocagem a $4{ }^{\circ} \mathrm{C} / 72 \mathrm{~h}$ foi atribuída à plasmina (WIKING et al., 2002).

O processo de microfiltração também pode alterar a atividade da plasmina. A retenção da plasmina foi similar a da caseína no processo de microfiltração em membrana com diâmetro de poro de 800 KDa, sendo sua atividade no retentado inversamente proporcional ao teor de proteínas do soro (AALTONEN e OLLIKAINEN, 2011), já que a presença dessas proteínas inibem a atividade da plasmina.

\subsection{Enzimas associadas à mastite}

O efeito da mastite (inflamação da glândula mamária) na qualidade do leite já está bem documentado (LE MARÉCHAL et al., 2011; FERNANDES et al., 2008; BARBANO et al., 2006; SANTOS et al., 2003; MA et al., 2000). A mastite ocasiona aumento da contagem de células somáticas (CCS), que está relacionado ao aumento de proteases, principalmente oriundas dos leucócitos, como as catepsinas D, G e B e a elastase, que podem degradar as $\beta$ - e $\alpha_{\text {s1 }}$-caseínas (LE MARÉCHAL et al., 2011).

O aumento da atividade enzimática acelera o desenvolvimento de defeitos sensoriais no leite como a rancidez e o sabor amargo, provocados pela lipólise e proteólise (SANTOS et al., 2003), resultando na diminuição da vida de prateleira de leites fluidos. As alterações sensoriais resultantes da alta contagem de células somáticas podem permanecer no leite mesmo após pasteurização ou tratamento UHT (LE MARÉCHAL et al., 2011).

Leite pasteurizado ou UHT provenientes de animais com mastite são caracterizados por níveis elevados de proteases e lipases nativas, principalmente devido ao aumento da contagem de células somáticas e tem sido demonstrado que são mais susceptíveis ao desenvolvimento de off-flavors em relação a leites com baixa CCS (FERNANDES et al., 2008; SANTOS et al., 2003). Ma et al. (2000) observaram que, em leite 
pasteurizado com alta CCS, o aumento dos ácidos graxos livres e da hidrólise da caseína foi três vezes maior do que no leite pasteurizado com baixa CCS.

A alta contagem de células somáticas em leite cru é associada à proteólise de $\beta$-caseína e $\alpha_{\mathrm{s}}$-caseína em leites UHT, o que pode levar a defeitos de qualidade durante o armazenamento (FERNANDES et al., 2008). Portanto, é recomendável que o leite cru utilizado para a produção de leite fluido contenha baixa contagem de células somáticas, para evitar a degradação das frações de caseína e a ocorrência de defeitos de qualidade durante o armazenamento do produto.

As enzimas provenientes das células somáticas podem ser o fator limitante da vida de prateleira do leite pasteurizado, produzido a partir de leite cru com baixa contagem microbiana. Essas enzimas serão responsáveis pela produção de defeitos sensoriais no produto final (BARBANO et al., 2006). A microfiltração, ao retirar todas as células somáticas do leite, pode evitar alterações causadas pela liberação de suas enzimas que ocorre nos tratamentos térmicos convencionais, contribuindo para aumentar a vida de prateleira do leite pasteurizado (GÉSAN-GUIZIOU, 2010).

\subsection{Enzimas de microrganismos psicrotróficos}

As proteases extracelulares dos psicrotróficos atuam preferencialmente sobre a א-caseína (RECIO, 2000), seguida da $\beta$-caseína, hidrolisada por essas enzimas mais rapidamente que a $\alpha$-caseína (HACHANA et al., 2010).

A atividade proteolítica de Pseudomonas sp isoladas de 9 amostras de leite cru foi investigada por Adams et al. (1976). Os resultados mostraram que a maioria das cepas degradava a א-caseína antes mesmo de a população atingir $10^{4} \mathrm{UFC} / \mathrm{mL}$, e que a degradação da $\beta$-caseína foi mais pronunciada quando as populações foram maiores que $10^{6}-10^{7} \mathrm{UFC} / \mathrm{mL}$. No entanto, Nörnberg et al. (2009) não encontraram correlação entre a atividade proteolítica e as contagens de psicrotróficos, sugerindo que a proteólise está associada a linhagens específicas de bactérias.

A produção de enzimas hidrolíticas termorresistentes por bactérias psicrotróficas pode ocasionar alterações indesejáveis no leite UHT, como a gelificação e o desenvolvimento de sabor amargo (DATTA e DEETH, 2003). A utilização da microfiltração do leite, seguida de pasteurização, auxilia na obtenção de um produto com baixa população microbiana e, consequentemente, com número de psicrotróficos remanescentes reduzido. A redução dos psicrotróficos e consequente produção de suas enzimas pode aumentar a vida de prateleira do leite pasteurizado.

\section{Microfiltração}

\subsection{Princípio}

A tecnologia de microfiltração (MF) utiliza membranas para concentração e/ou separação de certos constituintes do leite e está baseada na permeabilidade seletiva de um ou mais constituintes através da membrana (CHERYAN, 1998). O tamanho do poro da membrana varia de 0,1 a $10 \mu \mathrm{m}$, o que significa que a MF pode ser utilizada para o fracionamento de proteínas e, principalmente, para remoção de microrganismos, células somáticas e gordura residual, sendo eficiente na redução de esporos, conservando as características sensoriais e nutricionais iniciais, otimizando a qualidade do produto final (MAUBOIS, 2002; TE GIFFEL e VAN DER HORST, 2004).

O processo de separação por membranas começou a ser utilizado na indústria de laticínios na década de 1970. Entretanto, o processo de microfiltração industrial somente foi viabilizado nos anos 1990, com o advento das membranas cerâmicas e o desenvolvimento do conceito PTU (Pressão Transmembrana Uniforme) (POULIOT, 2008), que foi introduzido com o processo denominado Bactocatch $^{\text {TM }}$ (MAUBOIS, 2002). Nesse sistema, faz-se uma recirculação de parte do permeado pressurizado, para manter a pressão uniforme em toda a extensão da membrana e garantir um fluxo de permeado constante, ao diminuir a perda de carga ao longo da membrana e, consequentemente, as incrustações. Entretanto, a utilização de um sistema adicional de bomba ocasiona altos custos operacionais. Por este motivo, novos sistemas foram desenvolvidos como alternativas ao uso do sistema PTU, com menor consumo de energia e economia no investimento, sem necessidade de bomba para recircular o permeado. O primeiro sistema alternativo ao PTU, conhecido como Membralox $\mathrm{GP}^{\circledR}$, é baseado na variação contínua da porosidade do suporte da membrana. O segundo, chamado de Isoflux ${ }^{\circledR}$, é baseado na variação contínua da espessura da camada da membrana (MAUBOIS, 2002; SKRZYPEK e BURGER, 2010).

\subsection{Remoção de microrganismos, esporos e células somáticas}

A utilização da MF com membranas de poro de 1,4 $\mu \mathrm{m}$ permite a redução do número de microrganismos totais e uma remoção completa de células somáticas do leite desnatado (SABOYA e MAUBOIS, 2000; TE GIFFEL e VAN DER HORST, 2004), resultando em um leite com baixa contagem de microrganismos, aumentando, dessa forma, a qualidade, segurança e vida de prateleira do leite e de seus derivados.

Essa tecnologia isolada pode promover redução de 4 a 5 ciclos logarítmicos na contagem de microrganismos totais, mas a legislação da maioria dos países exige a 
posterior pasteurização do leite (GOFF e GRIFFITHS, 2006). Elwell e Barbano (2006) relataram uma redução bacteriana de 3,8 ciclos log na microfiltração e de 5,6 ciclos log no processo (com utilização de Membralox ${ }^{\circledast}$ ) seguido de pasteurização a $72{ }^{\circ} \mathrm{C}$ por $15 \mathrm{~s}$ em leite desnatado. Uma redução de 2-3 ciclos log em leite bovino e caprino também foi obtida com processo de microfiltração (BEOLCHINI et al., 2005). Com a utilização de membrana Isoflux ${ }^{\circledast}$, uma redução de aproximadamente 4 ciclos log foi obtida em leite desnatado (SKRZYPEK e BURGER, 2010). Em escala laboratorial, uma redução de $94,6 \%$ a $99,9 \%$ no número de Mycobacterium avium ssp. paratuberculosis foi realizada com a utilização de membrana Millipore ${ }^{\circledR} 1,2 \mu \mathrm{m}$ (GRANT et al., 2005).

A microfiltração também tem sido utilizada em combinação com o processo de pulsos elétricos e se conseguiu uma redução de microrganismos mesófilos maior que 4,0 ciclos log, comparável ao processo de microfiltração seguido de pasteurização (RODRÍGUESGONZÁLEZ et al., 2011).

Para reduzir os microrganismos de produtos termicamente sensíveis como o colostro, que é fonte de vários produtos nutracêuticos, têm sido utilizados a microfiltração juntamente com sistemas de alta pressão (GOSCH et al., 2014).

O processo de microfiltração também é eficiente na remoção de esporos. Uma redução de $10^{5}$ esporos/ $\mathrm{mL}$ de $B$. cereus e Clostridium sp de leite desnatado foi obtida utilizando membrana cerâmica com poro de 1,0 $\mu \mathrm{m}$ (GUERRA et al., 1997). Da mesma forma, foi observada uma redução de 4,5 ciclos log de esporos de Bacillus anthracis em leite microfiltrado (TOMASULA et al., 2011). Por outro lado, o processo de microfiltração pode induzir a germinação dos esporos devido à temperatura utilizada $\left(35-50{ }^{\circ} \mathrm{C}\right)$ ou por danos causados na estrutura dos esporos (TOMASULA et al., 2011).

Com o intuito de prevenir a germinação de esporos termofílicos durante o processo de microfiltração convencional, FRISTICH e MORARU, (2008) otimizaram os parâmetros para realização de microfiltração a frio $\left(6^{\circ} \mathrm{C}\right)$. A remoção de células vegetativas bacterianas, esporos e células somáticas foi eficaz, mantendo ao mesmo tempo uma composição de proteína no leite microfiltrado muito próxima à da inicial do leite desnatado, com fluxo variando de 60 a $80 \mathrm{~L} / \mathrm{h} / \mathrm{m}^{2}$, de acordo com os parâmetros operacionais.

Além da produção de leite para consumo com vida útil prolongada, a microfiltração tem sido utilizada para remoção de microrganismos e esporos de leite para elaboração de bebida láctea probiótica (DEBON et al., 2012) e queijos (DONG et al., 2009; SCHREIER et al., 2010).
A remoção de esporos e células somáticas é particularmente importante porque eles não são destruídos pelo processo de pasteurização (FRISTICH e MORARU, 2008). Além disso, os esporos podem germinar no produto, o que ressalta mais uma vez a vantagem do uso de microfiltração para remoção dos esporos e células somáticas (ELWELL e BARBANO, 2006).

Em geral, a remoção de microrganismos por membranas com diâmetro de poro de 1,4 um não modifica a composição do leite microfiltrado (DONG et al., 2009; TOMASULA et al., 2011).

Apesar de a remoção de esporos de Bacillus anthracis ser mais efetiva com a utilização de membrana com poro $0,8 \mu \mathrm{m}$, somente a membrana com poro de 1,4 $\mu \mathrm{m}$ permitiu uma transmissão completa da caseína (TOMASULA et al., 2011). Por outro lado, Morin et al. (2004), ao microfiltrar leitelho, observaram menor transmissão de proteína em membrana com poro de 1,4 um em comparação com a de 0,8 $\mu \mathrm{m}$, o que indica desvio da lei de Ferry. Esta lei de filtração indica que, para uma partícula de um dado diâmetro, um aumento no tamanho dos poros da membrana resulta em maior transmissão do componente. O resultado observado pelos autores pode ser atribuído às incrustações na membrana e a formação da camada gel polarizada.

\subsection{Uso da microfiltração para estender a vida de prateleira do leite pasteurizado}

As tecnologias empregadas para estender a vida de prateleira do leite incluem o uso da bactofugação ou de membranas de microfiltração (MF), mas a MF é mais efetiva na redução da contagem microbiana (TE GIFFEL e VAN DER HORST, 2004; GÉSAN-GUIZIOU, 2010).

A tecnologia de MF é uma alternativa não térmica de processamento do leite fluido, com consequências benéficas na sua qualidade sensorial e vida de prateleira. A microfiltração do leite associa as vantagens da maior qualidade sensorial do leite pasteurizado em relação ao UHT e esterilizado, com a praticidade de um produto de vida de prateleira relativamente mais longa do que o produto apenas pasteurizado, mas sem prescindir da cadeia de frio para sua distribuição e comercialização (SABOYA e MAUBOIS, 2000).

A microfiltração seguida de pasteurização é uma tecnologia já aplicada em vários países da Europa, nos Estados Unidos, Canadá e Austrália, para estender a vida útil do leite pasteurizado (MAUBOIS, 2002; POULIOT, 2008).

O leite Marguerite ${ }^{\circledast}$ foi o primeiro leite microfiltrado produzido na França. O produto é obtido a partir da mistura de creme tratado termicamente $\left(95^{\circ} \mathrm{C} / 20 \mathrm{~s}\right)$ e leite desnatado microfiltrado (membrana com diâmetro de poro de 1,4 $\mu \mathrm{m}$ ), seguido de envase asséptico em 
garrafas plásticas. Legalmente, o produto é considerado leite cru, sendo a França o único país que permite a comercialização de leite cru microfiltrado. A vida de prateleira do produto armazenado a $4-6{ }^{\circ} \mathrm{C}$ é de até 3 semanas, comparado a 3 dias para o leite cru não microfiltrado. Em 2008, foram produzidos 10 milhões de litros desse leite (CARVALHO e MAUBOIS, 2009).

Em outros países europeus e no Canadá, o leite microfiltrado sofre tratamento térmico de pasteurização (72 ${ }^{\circ} \mathrm{C} / 15 \mathrm{~s}$ ) antes de ser envasado assepticamente, e sua vida útil se estende por até 35 dias. Esse produto apresenta ampla aceitação pelos consumidores devido às características sensoriais (como ausência de sabor de cozido) e maior vida de prateleira que o leite pasteurizado (BINETTI et al., 2001).

Hoffmann et al. (2006) afirmam que as propriedades sensoriais do leite microfiltrado são comparáveis às do leite pasteurizado. No entanto, Kaufmann (2009) apud Lorenzen et al. (2011) concluiu que o leite de vida de prateleira estendida também apresentava um sabor de cozido, porém menos pronunciado que o leite UHT. Kaufmann e Kulosik (2007), novamente citados por Lorenzen et al. (2011), notaram um sabor estranho no final da vida de prateleira, que foi atribuído à proteólise, pela inativação insuficiente de enzimas endógenas ou de origem microbiana. Apesar disso, os autores não observaram relação entre alterações no perfil de aroma e o tempo de estocagem do leite.

Em outro estudo, Hoffmann et al. (1996) realizaram testes com MF para produção de leite com vida de prateleira estendida, utilizando o sistema Tetra Pak Filtration Systems. Os autores observaram que uma combinação de microfiltração e pasteurização HTST ( high temperature short time) com envase em condições assépticas produziu um leite com boas propriedades sensoriais. O leite assim tratado é uma alternativa à ultrapasteurização para estender a vida de prateleira de leite refrigerado. Quando a temperatura de distribuição utilizada foi de 5 a $6{ }^{\circ} \mathrm{C}$, a vida de prateleira do leite microfiltrado pasteurizado foi cerca de cinco semanas. Quando a temperatura de armazenamento foi de 8 a $10{ }^{\circ} \mathrm{C}$, o produto alcançou um máximo de duas a três semanas de vida útil. No estudo realizado por Elwell e Barbano (2006), o leite microfiltrado pasteurizado apresentou vida de prateleira de 46 e 32 dias, quando o produto foi armazenado a 4,2 e $6,1^{\circ} \mathrm{C}$, respectivamente.

Existe pouca informação sobre os fatores que limitam a vida de prateleira dos leites microfiltrados pasteurizados. Em um estudo realizado por Schmidt et al. (2012), observou-se que, apesar de a contagem total de microrganismos após a microfiltração ser baixa (<1UFC/ $\mathrm{mL}$ ) e similar entre os produtos analisados, o número de microrganismos no fim da vida de prateleira do leite microfiltrado pasteurizado apresentou grande variação (de $<1$ a 8 log UFC/ml) até mesmo em embalagens do mesmo lote de produção. Essa inesperada variação microbiana no fim da vida do produto foi atribuída à baixa contagem inicial do leite microfiltrado pasteurizado, que pode ter favorecido o desenvolvimento diversificado de espécies microbianas (SCHMIDT et al., 2012). Apesar da diversidade observada no estudo de Schmidt et al. (2012), o principal grupo de microrganismos deteriorantes em leites microfiltrados pasteurizados foi de bactérias Gram negativas (G-) recontaminantes (dos gêneros Acinetobacter e Psycrobacter) e bactérias formadoras de esporos, como Paenibacillus sp. e Bacillus cereus. A presença de esporos no leite pasteurizado também foi determinada como limitante da vida de prateleira por Fromm e Boor (2004). A biodiversidade de microrganismos em leite microfiltrado foi novamente observada durante armazenamento de leite microfiltrado cru a 4 e a $8{ }^{\circ} \mathrm{C}$, sendo Stenotrophomonas, Pseudomonas e Delftia os gêneros dominantes após 3 dias de armazenamento, enquanto que após 7 dias, prevaleceu o gênero Pseudomonas (RASOLOFO et al., 2010).

A contagem total de microrganismos viáveis foi maior em leites com vida de prateleira estendida obtidos por microfiltração quando comparada a dos obtidos por tratamentos térmicos de $123-127{ }^{\circ} \mathrm{C} / 1-5 \mathrm{~s}$ (LORENZEN et al., 2011). Nesse estudo, não foi detectado crescimento de enterococos e enterobactérias nas amostras analisadas. Também não foram detectados bacilos psicrotróficos, mas seu crescimento pode ter sido inibido pela presença de outros contaminantes viáveis.

Em estudo recente (SCHMIDT et al., 2012), as alterações enzimáticas foram fatores limitantes à extensão da vida de prateleira de leite microfiltrado pasteurizado. Essas alterações foram ocasionadas pela presença de enzimas microbianas no produto, e foram mais pronunciadas nas amostras armazenadas a $10{ }^{\circ} \mathrm{C}$ em comparação com as amostras armazenadas a 4 e $8^{\circ} \mathrm{C}$.

\section{Incrustações e limpeza de membranas}

O permeado corresponde à fração que atravessa a membrana semipermeável, seu fluxo é a medida da massa de permeado coletado em função do tempo decorrido pela área de membrana. Por isso, o fluxo de permeado é um parâmetro crítico na determinação da eficiência do processo de microfiltração. O declínio do fluxo de permeado em função do tempo de processamento de uma solução multicomponente, em comparação com a água pura, pode ser causado pela polarização da concentração e por incrustações (também conhecidas como fouling).

A incrustação nas membranas é um fenômeno muito complexo, principalmente quando o fluido é composto de leite ou derivados, devido à contribuição dos diferentes constituintes do leite, sendo as proteínas e 
os minerais (cálcio e fosfato) os principais componentes associados às incrustações (MARSHALL e DAUFIN, 1995). Micelas de caseína são consideradas as principais responsáveis pela formação do depósito na superfície da membrana e os íons cálcio também desempenham um papel nas incrustações irreversíveis, provavelmente pelo estabelecimento de ligações entre a membrana e as micelas e entre as próprias micelas (JIMENEZLOPEZ et al., 2008). A incrustação pode ocorrer de várias formas: pela deposição de proteínas desnaturadas ou aglomeradas na superfície da membrana, ou pela adsorção de proteínas no interior da estrutura dos poros das membranas, o que dificulta sua remoção.

Para minimizar a compactação da camada gel polarizada e impedir a rejeição das proteínas no processo de microfiltração de leite com membranas cerâmicas com diâmetro de poro de 1,4 um, têm sido propostas condições otimizadas de velocidade $(6 \mathrm{~m} / \mathrm{s})$ e pressão transmembrana (<30 kPa) (CHERYAN, 1998; SABOYA e MAUBOIS, 2000).

A eficácia do procedimento de limpeza de membranas é importante para garantir seu desempenho, seletividade e vida útil, sendo tema de diversos trabalhos (BLANPAIN-AVET et al., 2004, 2009; D'SOUZA e MAWSON, 2005; POPOVIĆ et al., 2009).

Na limpeza da membrana, geralmente são utilizados detergentes alcalinos para remoção de resíduos de proteínas e gorduras e, posteriormente, ácidos, principalmente para dissolver precipitados de sais inorgânicos (D'SOUZA e MAWSON, 2005). Entretanto, Blanpain-Avet et al. (2004) têm recomendado o uso exclusivo de hidróxido de sódio $(\mathrm{NaOH})$, uma vez que observaram aumento gradual no fouling residual durante a limpeza com ácido nítrico.

A limpeza de membranas cerâmicas com diâmetro de poro de 50 e 200 nm com soda foi também mais eficiente que a realizada com agentes de limpeza alcalinos comerciais. Neste estudo foram utilizados, além da soda, dois agentes de limpeza: um com 15\%-30\% de óxido de amina e cerca de $5 \%$ de enzimas proteolíticas (D1); e outro com 5\%-15\% de fosfonatos e 5\%-15\% de sais orgânicos (D2) na combinação de 0,8\%+0,5\% e $1,2 \%+0,75 \%$ de D2/D1. A melhor recuperação do fluxo inicial para membrana com diâmetro de poro de $50 \mathrm{~nm}$ ocorreu com a utilização de $\mathrm{NaOH}$ 1,0\% (POPOVIĆ et al., 2009).

Diferentes estratégias para controle das incrustações e otimização dos processos de microfiltração estão disponíveis na literatura (GUERRA et al., 1997; FRISTICH e MORARU, 2008; MASKOOKI et al., 2008; MIRZAIE e MOHAMMADI, 2012). Entre elas destacam-se o uso do conceito de PTU (pressão transmembrana uniforme) com altas velocidades, promoção de turbulências, backpulsing (também conhecido como backwashing, backflushing que é realizado por meio da promoção do fluxo no sentido contrário, ou seja, reversão da pressão transmembrana), utilização de ultrassom ou campos elétricos, entre outros (BRANS et al., 2004).

O processo de microfiltração com sistema PTU combinado com backpulsing (mesmo com baixa velocidade de alimentação 0,5-1,0 m/s) conseguiu reduções de 4 a 5 ciclos logarítmicos de esporos em leite desnatado. Contudo, a eficácia do backpulsing depende da frequência, duração e perfil de pressão e também é altamente dependente da composição da alimentação (GUERRA et al., 1997).

A utilização de ultrassom durante o processo de microfiltração do leite aumentou o fluxo de permeado (MIRZAIE e MOHAMMADI, 2012). Os autores estudaram o efeito do ultrassom sobre o fluxo de permeado e avaliaram vários parâmetros, tais como a pressão de alimentação, a potência de irradiação, a distância entre a fonte de irradiação e a superfície da membrana e a irradiação de impulsos. Um aumento de 5 vezes no fluxo foi obtido a uma pressão de 0,5 bar, potência de $40 \mathrm{~W}$ e distância de 2,6 cm entre a fonte de irradiação e a superfície da membrana.

O ultrassom também pode ser utilizado para otimizar os processos de limpeza. Em estudo realizado por Maskooki et al. (2008), o uso de ultrassom individualmente e em conjunto com o composto químico usado como detergente EDTA (ácido etilenodiamino tetrassódico) resultou em maior eficiência de limpeza da membrana quando comparado ao uso de EDTA sozinho.

\section{Conclusão}

As condições de refrigeração do leite cru são decisivas para a qualidade e vida de prateleira do leite pasteurizado, pois longos períodos ou temperaturas inadequadas podem favorecer o desenvolvimento de microrganismos psicrotróficos e a produção de suas enzimas. A microfiltração, em combinação com a pasteurização, pode ser uma alternativa para prolongar a vida de prateleira do leite pasteurizado por meio da remoção de microrganismos e células somáticas do leite cru. A otimização dos parâmetros do processo de microfiltração e do procedimento de limpeza, mais o desenvolvimento de novos sistemas de membrana são fundamentais para a implementação dessa tecnologia na indústria, que necessita de membranas com bom desempenho e vida útil prolongada. Ao reduzir a população bacteriana a níveis muito baixos, a combinação de microfiltração e pasteurização do leite resulta num produto sem os defeitos de sabor do leite UHT, mas com vida de prateleira estendida sob refrigeração. 
Uso de microfiltração para melhoria da qualidade e extensão da vida de prateleira de leite pasteurizado ANTUNES, V. C.

\section{Referências}

AALTONEN, T.; OLLIKAINEN, P. Effect of microfiltration of milk on plasmin activity. International Dairy Journal, Wembley, v. 21, n. 4, p. 193-197, 2011. http://dx.doi.org/10.1016/j. idairyj.2010.12.002

ADAMS, D. M.; BARACH, J. T.; SPECK, M. L. Effect of psychrotrophic bacteria from raw milk on milk proteins and stability of milk proteins to ultrahigh temperature treatment. Journal of Dairy Science, Lancaster, v. 59, n. 5, p. 823-827, 1976. http://dx.doi.org/10.3168/jds.S0022-0302(76)84282-8

BARBANO, D. M.; MA, Y.; SANTOS, M. V. Influence of raw milk quality on fluid milk shelf life. Journal of Dairy Science, Lancaster, v. 89, p. E15-E19, 2006. Suplemento. http://dx.doi. org/10.3168/jds. S0022-0302(06)72360-8

BEOLCHINI, F.; CIMINI, S.; MOSCA, L.; VEGLIO, F.; BARBA, D. Microfiltration of bovine and ovine milk for the reduction of microbial content: effect of some operating conditions on permeate flux and microbial reduction. Separation Science and Technology, New York, v. 40, n. 4, p. 757-772, 2005. http:// dx.doi.org/10.1081/SS-200048160

BLANPAIN-AVET, P.; MIGDAL, J. F.; BÉNÉZECH, T. The effect of multiple fouling and cleaning cycles on a tubular ceramic microfiltration membrane fouled with a whey protein concentrate. Membrane performance and cleaning efficiency. Food and Bioproducts Processing, Warks, v. 82, n. 3, p. 231-243, 2004. http://dx.doi.org/10.1205/fbio.82.3.231.44182

BLANPAIN-AVET, P.; MIGDAL, J. F.; BÉNÉZECH, T. Chemical cleaning of a tubular ceramic microfiltration membrane fouled with a whey protein concentrate suspension: Characterization of hydraulic and chemical cleanliness. Journal of Membrane Science, Amsterdam, v. 337, n. 1-2, p. 153-174, 2009. http:// dx.doi.org/10.1016/j.memsci.2009.03.033

BINETTI, A. G.; BAILO, N. B.; REINHEIMER, J. A. Aplicaciones de la microfiltración en la industria láctea. Tecnología Láctea Latinoamericana, Argentina, v. 6, n. 24, p. 48-52, 2001.

$\mathrm{BOOR}, \mathrm{K}$. J. Fluid dairy product quality and safety: looking to the future. Journal of Dairy Science, Lancaster, v. 84, n. 1, p. 1-11, 2001. http://dx.doi.org/10.3168/jds. S0022-0302(01)74445-1

BRANS, G.; SCHROEN, C. G. P. H.; VAN DER SMAN, R. G. M.; BOOM, R. M. Membrane fractionation of milk: state of the art and challenges. Journal of Membrane Science, Amsterdam, v. 243 , n. 1-2, p. 263-272, 2004. http://dx.doi.org/10.1016/j. memsci.2004.06.029

BRASIL. Ministério de Estado da Agricultura, Pecuária e Abastecimento. Instrução Normativa n. 51, de 18 de setembro de 2002. Regulamento técnico de identidade e qualidade de leite cru refrigerado. Diário Oficial da República Federativa do Brasil, Poder Executivo, Brasília, DF, 20 set. 2002. Seção 1, p. 13-22.
BRASIL. Ministério de Estado da Agricultura, Pecuária e Abastecimento. Instrução Normativa n. 62, de 29 de dezembro de 2011. Regulamento técnico de identidade e qualidade de leite cru refrigerado. Diário Oficial da República Federativa do Brasil, Poder Executivo, Brasília, DF, 29 dez. 2011. Seção 1, p. 6-11.

CARVALHO, A. F.; MAUBOIS, J. L. Applications of membrane technologies in the dairy industry. In: COIMBRA, J. S. R.; TEIXEIRA, J. A. Engineering Aspects of Milk and Dairy Products. Braga: Hardback, 2009. p. 33-56. PMid:19245514. http://dx.doi.org/10.1201/9781420090390-c3

CHAVAN, S. R.; KHEDKAR, C. D.; JANA, A. H. UHT milk processing and effect of plasmin activity on shelf life: A Review. Comprehensive Reviews in Food Science and Food Safety, Chicago, v. 10, n. 5, p. 251-268, 2011. http://dx.doi.org/10.1111/ j.1541-4337.2011.00157.x

CHEN, L.; DANIEL, R. M.; COOLBEAR, T. Review impact of protease and lipase activity and milk powders. International Dairy Journal, Wembley, v. 13, n. 4, p. 255-275, 2003.

\section{CHERYAN, M. Ultrafiltration and Microfiltration Handbook.} Boca Raton: CRC Press, 1998. 597 p.

COUSIN, M. A. Presence and activity of psychrotrophic microrganisms in milk and dairy products: a review. Journal of Food Protection, Ames, v. 45, n. 2, p. 172-207, 1982.

CRUDDEN, A.; FOX, P. F.; KELLY, A. L. Factors affecting the hydrolytic action of plasmin in milk. International Dairy Journal, Wembley, v. 15, n. 4, p. 305-313, 2005. http://dx.doi. org/10.1016/j.idairyj.2004.08.008

DATTA, N.; DEETH, H. C. Diagnosing the cause of proteolysis in UHT milk. LWT - Food Science and Technology, Amsterdam, v. 36, n. 2, p. 173-182, 2003. http://dx.doi.org/10.1016/S00236438(02)00214-1

DEBON, J.; PRUDÊNCIO, E. S.; PETRUS, J. C. C.; FRITZENFREIRE, C. B.; MÜLLER, C. M. O.; AMBONI, R. D. M. C.; VIEIRA, C. R. W. Storage stability of prebiotic fermented milk obtained from permeate resulting of microfiltration process. LWT - Food Science and Technology, Amsterdam, v. 47, n. 1, p. 96-102, 2012. http://dx.doi.org/10.1016/j.Iwt.2011.12.029

DE JONGHE, V.; COOREVITS, A.; VAN HOORDE, K.; MESSENS, W.; VAN LANDSCHOOT, A.; HEYNDRICKX, M. Influence of storage conditions on the growth of Pseudomonas species in refrigerated raw milk. Applied and Environmental Microbiology, Washington, v. 77, n. 2, p. 460-470, 2011. PMid:21115713 PMCid:PMC3020527. http://dx.doi.org/10.1128/AEM.00521-10

DONG, J. Y.; CHEN, L. J.; MAUBOIS, J. L.; MA, Y. Influence of medium-concentration factor microfiltration treatment on the characteristics of low-moisture Mozzarella cheese. Dairy Science and Technology, Netherlands, v. 89, n. 2, p. 139-154, 2009. http://dx.doi.org/10.1051/dst/2009002 
Uso de microfiltração para melhoria da qualidade e extensão da vida de prateleira de leite pasteurizado ANTUNES, V. C.

D'SOUZA, N. M. D.; MAWSON, A. J. Membrane cleaning in the dairy industry: A Review. Critical Reviews in Food Science and Nutrition, Boca Raton, v. 45, n. 2, p. 125-134, 2005. PMid:15941016. http://dx.doi.org/10.1080/10408690490911783

ELWELL, M. W.; BARBANO, D. M. Use of microfiltration to improve fluid milk quality. Journal of Dairy Science, Lancaster, v. 89, p. E20-E30, 2006. Suplemento. http://dx.doi.org/10.3168/ jds.S0022-0302(06)72361-X

EMBRAPA. Gado de Leite. Produção, Industrialização e Comercialização: Consumo. Juiz de Fora: Embrapa, 2013. Disponível em: <http://www.cnpgl.embrapa.br>. Acesso em: 05 set. 2013

FERNANDES, A. M.; BOVO, F.; MORETTI, T. S.; ROSIM, R. E.; LIMA, C. G.; OLIVEIRA, C. A. F. Relationship between the somatic cell count in raw milk and the casein fractions of UHT milk. Australian Journal of Dairy Technology, North Melbourne, v. 63, n. 2, p. 45-49, 2008

FRITSCH, J.; MORARU, C. I. Development and optimization of a carbon dioxide-aided cold microfiltration process for the physical removal of microorganism and somatic cells from skim milk. Journal of Dairy Science, Champaign, v. 91, n. 10, p. 3744-3760, 2008. PMid:18832196. http://dx.doi.org/10.3168/ jds.2007-0899

FROMM, H. I.; BOOR, K. J. Characterization of pasteurized fluid milk shelf-life attributes. Journal of Food Science, Chicago, v. 69, n. 8, p. 207-214, 2004. http://dx.doi. org/10.1111/j.1365-2621.2004.tb09889.x

GÉSAN-GUIZIOU, G. Removal of bacteria, spores and somatic cells from milk by centrifugation and microfiltration techniques. In: GRIFFITHS, M. W. (Ed.). Improving the safety and quality of milk. Boca Raton: CRC Press, 2010. p. 349-372. http://dx. doi. org/10.1533/9781845699420.4.349

GOSCH, T.; APPRICH, S.; KNEIFEL, W.; NOVALIN, S. A combination of microfiltration and high pressure treatment for the elimination of bacteria in bovine colostrums. International Dairy Journal, Wembley, v. 34, n. 1, p. 41-46, 2014. http://dx.doi. org/10.1016/j.idairyj.2013.06.014

GOFF, H. D.; GRIFFITHS, M. W. Major advances in fresh milk and milk products: fluid milk products and frozen desserts. Journal of Dairy Science, Lancaster, v. 89, n. 4, p. 1163-1176, 2006. http://dx.doi.org/10.3168/jds.S0022-0302(06)72185-3

GRANT, I. R.; WILLIAMS, A. G.; ROWE, M. T.; MUIR, D. D. Investigation of the impact of simulated commercial centrifugation and microfiltration conditions on levels of Mycobacterium avium ssp. paratuberculosis in milk. International Journal of Dairy Technology, Huntingdon, v. 58, n. 3, p. 138-142, 2005. http:// dx.doi.org/10.1111/j.1471-0307.2005.00201.x

GUERRA, A.; JONSSON, G.; RASMUSSEN, A.; WAAGNER NIELSEN, E.; EDELSTEN, D. Low cross-flow velocity microfiltration of skim milk for removal of bacterial spores. International Dairy
Journal, Wembley, v. 7, n. 12, p. 849-861, 1997. http://dx.doi. org/10.1016/S0958-6946(98)00009-0

GUINOT-THOMAS, P.; AMMOURY, A. M.; LE ROUX, Y.; LAURENT, F. Study of proteolysis during storage of raw milk at $4{ }^{\circ} \mathrm{C}$ : Effect of plasmin and microbial proteinases. International Dairy Journal, Wembley, v. 5, p. 685-697, 1995. http://dx.doi.org/10.1016/09586946(95)00043-3

HACHANA, Y.; KRAIEM, K.; PAAPE, M. J. Effect of plasmin, milk somatic cells and psychrotrophic bacteria on casein fractions of ultra high temperature treated milk. Food Science and Technology Research, Japan, v. 16, n. 1, p. 79-86, 2010. http:// dx.doi.org/10.3136/fstr.16.79

HARYANI, S.; DATTA, N.; ELLIOTT, A. J.; DEETH, H. C. Production of proteinases by psychrotrophic bacteria in raw milk stored at low temperature. Australian Journal of Dairy Technology, North Melbourne, v. 58, n. 1, p. 15-20, 2003.

HAYES, M. C.; BOOR, K. Raw milk and fluid milk products. In: MARTH, E. H.; STEELE, J. L. Applied Dairy Microbiology. 2th ed. New York: Marcel Dekker, 2001. p. 59-75.

HOFFMANN, W.; KLOBES, H.; KIESNER, C. H. R.; SUHREN, G.; KRUSCH, U.; CLAWIN-RÄDECKER, I.; LARSEN, P. H. Use of microfiltration for the production of pasteurized milk with extended shelf life. Bulletin of International Dairy Federation, Brussels, v. 311, n. 12, p. 45-46, 1996.

HOFFMANN, W.; KIESNER, C.; KRUSCH, U.; CLAWINRÄDECKER, I.; MARTIN, D.; EINHOFF, K.; LORENZEN, P. C.; MEISEL, H.; HAMMER, P.; SUHREN, G.; TEUFEL, P. Processing of extended shelf life milk using microfiltration. International Journal of Dairy Technology, Huntingdon, v. 59, n. 4, p. 229-235, 2006. http://dx.doi.org/10.1111/j.14710307.2006.00275.x

IZIDORO, T. B.; SPINA, T. L. B.; LIMA, M. T.; NOBILE, C.; TUASEK, S. O.; PEREIRA, J. G.; PINTO, J. P. A. N. Resfriamento marginal: multiplicação da microbiota psicrotrófica e o metabolismo acidificante da microbiota láctea. In: CONGRESSO BRASILEIRO DE QUALIDADE DO LEITE, 4., 2010, Florianópolis. Anais... Florianópolis: CBQL, 2010. 1 CD-ROM.

JIMENEZ-LOPEZ, A. J. E.; LECONTE, N.; DEHAINAULT, O.; GENESTE, C.; FROMONT, L.; GÉSAN-GUIZIOU, G. Role of milk constituents on critical conditions and deposit structure in skim milk microfiltration $(0,1 \mu \mathrm{m})$. Separation and Purification Technology, Amsterdam, v. 61, n. 1, p. 33-43, 2008. http:// dx.doi.org/10.1016/j.seppur.2007.09.023

LE MARÉCHAL, C.; VAUTOR, R. T. E.; LE LOIR, Y. Mastitis impact on technological properties of milk and quality of milk products: a review. Dairy Science and Technology, Netherlands, v. 91, n. 3, p. 247-282, 2011. http://dx. doi.org/10.1007/s13594-011-0009-6

LISITA, M. O. Influência da Variação da Temperatura de Armazenamento de Leite Cru na Vida De Prateleira de Leite Uht em Embalagem Flexível e Estocagem Sob Luz. 
Uso de microfiltração para melhoria da qualidade e extensão da vida de prateleira de leite pasteurizado ANTUNES, V. C.

2010. 129 f. Tese (Doutorado em Tecnologia de Alimentos)Faculdade de Engenharia de Alimentos, Universidade Estadual de Campinas, Campinas, 2010.

LORENZEN, P. H.; CLAWIN-RÄDECKER, I.; EINHOFF, K.; HAMMER, P.; HARTMANN, R.; HOFFMANN, W.; MARTIN, D.; MOLKENTIN, J.; WALTE, H. G.; DEVRESE, M. A survey of the quality of extended shelf life (ESL) milk in relation to HTST and UHT milk. International Journal of Dairy Technology, Huntingdon, v. 64, n. 2, p. 166-178, 2011. http://dx.doi. org/10.1111/j.1471-0307.2010.00656.x

LORENZETTI, D. K. Influência do Tempo e da Temperatura no Desenvolvimento de Microrganismos Psicrotróficos no Leite Cru de Dois Estados da Região Sul. 2006. 71 f. Dissertação (Mestrado em Tecnologia de Alimentos)-Universidade Federal do Paraná, Curitiba, 2006.

MA, Y.; RYAN, C.; BARBANO, D. M.; GALTON, D. M.; RUDAN, M.; BOOR, K. Effects of somatic cell count on quality and shelf life of pasteurized fluid milk. Journal of Dairy Science, Lancaster, v. 83 , n. 2, p. 264-274, 2000. http://dx.doi.org/10.3168/jds. S0022-0302(00)74873-9

MARSHALL, A. D.; DAUFIN, G. Physico-chemical aspects of membrane fouling by dairy fluids. In: VAN DER HORST, $\mathrm{H}$. C. Fouling and Cleaning in Pressure Driven Membrane Processes. Brussels: International Dairy Federation, 1995. chapt. 1, p. 9-29. (Special Issue, n. 9504).

MASKOOKI, A.; KOBAYASHI, T.; MORTAZAVI, S. A.; MASKOOKI, A. Effect of low frequencies and mixed wave of ultrasound and EDTA on flux recovery and cleaning of microfiltration membranes. Separation and Purification Technology, Amsterdam, v. 59, n. 1, p. 67-73, 2008. http://dx.doi.org/10.1016/j. seppur.2007.05.028

MAUBOIS, J. L. Membrane microfiltration: a tool for a new approach in dairy technology. Australian Journal of Dairy Technology, North Melbourne, v. 57, n. 2, p. 92-96, 2002.

MIRZAIE, A.; MOHAMMADI, T. Effect of ultrasonic waves on flux enhancement in microfiltration of milk. Journal of Food Engineering, London, v. 108, n. 1, p. 77-86, 2012. http://dx. doi. org/10.1016/j.jfoodeng.2011.07.026

MORIN, P.; JIMÉNEZ-FLORES, R.; POULIOT, Y. Effect of temperature and pore size on the fractionation of fresh and reconstituted buttermilk by microfiltration. Journal of Dairy Science, Lancaster, v. 87, n. 2, p. 267-273, 2004. http://dx.doi. org/10.3168/jds.S0022-0302(04)73165-3

NÖRNBERG, M. F. B. L.; TONDO, E. C.; BRANDELLI, A. Bactérias psicrotróficas e atividade proteolítica no leite cru refrigerado. Acta Scientiae Veterinariae, Porto Alegre, v. 37 , n. 2, p. 157-163, 2009.

NÖRNBERG, M. F. B. L.; FRIEDRICH R. S. C.; WEISS, R. D. N.; TONDO, E. C.; BRANDELLI, A. Proteolytic activity among psychrotrophic bacteria isolated from refrigerated raw milk.
International Journal of Dairy Technology, Huntingdon, v. 63 , n. 1, p. 41-46, 2010. http://dx.doi.org/10.1111/j.14710307.2009.00542.x

POPOVIĆ, S.; MILANOVIĆ, S.; ILIČIĆ, M.; DJURIĆ, M.; TEKIĆ, $M$. Flux recovery of tubular ceramic membranes fouled with whey proteins. Desalination, Philadelphia, v. 249, n. 1, p. 293-300, 2009. http://dx.doi.org/10.1016/j.desal.2008.12.060

POULIOT, Y. Membrane processes in dairy technology: from a simple idea to worldwide panacea. International Dairy Journal, Wembley, v. 18, n. 7, p. 735-740, 2008. http://dx.doi. org/10.1016/j.idairyj.2008.03.005

PRADO, B. M.; ISMAIL, B.; RAMOS, O.; HAYES, K. D. Thermal stability of plasminogen activators and plasminogen activation in heated milk. International Dairy Journal, Wembley, v. 17, n. 9, p. 1028-1033, 2007. http://dx.doi.org/10.1016/j. idairyj.2007.02.001

RASOLOFO, E. A.; ST-GELAIS, D.; LAPOINTE, G.; ROY, D. Molecular analysis of bacterial population structure and dynamics during cold storage of untreat and treated milk. International Journal of Food Microbiology, Amsterdam, v. 138, n. 1-2, p. 108-118, 2010. PMid:20137820. http://dx.doi. org/10.1016/j.ijfoodmicro.2010.01.008

RECIO, I.; GARCIA-RISCO, M. R.; RAMOS, M.; LOPEZ-FANDINO, R. Characterization of peptides produced by the action of psychrotrophic proteinases on k-casein. Journal of Dairy Research, Cambridge, v. 67, n. 4. p. 625-630, 2000. http:// dx.doi.org/10.1017/S002202990000443X

RODRÍGUES-GONZÁLEZ, O.; WALKLING-RIBEIRO, M.; JAYARAM, S.; GRIFFITHS, M. W. Factors affecting the inactivation of the natural microbiota of milkprocessed by pulsed electric fields and crossflow microfiltration. Journal of Dairy Research, Cambridge, v. 78, n. 3, p. 270 278, 2011.

SABOYA, L. V.; MAUBOIS, J. L. Current developments of microfiltration technology in the dairy industry. Lait, France, v. 80, n. 6, p. 541-553, 2000. http://dx.doi.org/10.1051/lait:2000144

SANVIDO, G. B. Efeito do Tempo de Armazenamento do Leite Cru e da Temperatura de Estocagem do Leite Pasteurizado Sobre sua Vida de Prateleira. 2007. 78 f. Dissertação (Mestrado em Tecnologia de Alimentos)-Faculdade de Engenharia de Alimentos, Universidade Estadual de Campinas, Campinas, 2007.

SANTOS, M. V.; MA, Y.; BARBANO, D. M. Effect of somatic cell count on proteolysis and lipolysis in pasteurized fluid milk during shelf-life storage. Journal of Dairy Science, Lancaster, v. 86, n. 8, p. 2491-2503, 2003. http://dx.doi.org/10.3168/jds.S00220302(03)73843-0

SANTOS, P. A.; SILVA, M. A. P.; SOUZA, C. M. S.; ISEPON, J. S.; OLIVEIRA, A. N.; NICOLAU, E. Efeito do tempo e da temperatura de refrigeração no desenvolvimento de microrganismos psicrotróficos em leite cru refrigerado coletado na macrorregião 
Uso de microfiltração para melhoria da qualidade e extensão da vida de prateleira de leite pasteurizado ANTUNES, V. C.

de Goiânia, GO. Revista Ciência Animal Brasileira, Goiânia, v. 10, n. 4 , p. $1237-1245,2009$

SANTOS, P. A.; SILVA, M. A. P.; MOREIRA, G. N.; BARROS, J. C.; OLIVEIRA, A. N.; NICOLAU, E. S. Evolução da proteólise do leite inoculado in vitro com Pseudomonas fluorescens. Boletim do CEPPA, Curitiba, v. 28, n. 2, p. 313-320, 2010.

SCHMIDT, V. S. J.; KAUFMANN, V.; KULOZIK, U.; SCHERER, S.; WENNING, M. Microbial biodiversity, quality and shelf life of microfiltered and pasteurized Extended Shelf Life (ESL) milk from Germany, Austria and Switzerland. International Journal of Food Microbiology, Amsterdam, v. 154, n. 1-2, p. 1-9, 2012. PMid:22240060. http://dx.doi.org/10.1016/j. ijfoodmicro.2011.12.002

SCHREIER, K.; SCHAFROTH, K.; THOMET, A. Application of cross-flow microfiltration to semi-hard cheese production from milk retentates. Desalination, Philadelphia, v. 250, n. 3, p. 10911094, 2010. http://dx.doi.org/10.1016/j.desal.2009.09.115

SKRZYPEK, M.; BURGER, M. Isoflux ${ }^{\circledR}$ ceramic membranes: practical experiences in dairy industry. Desalination, Philadelphia, v. 250, n. 3, p. 1095-1100, 2010. http://dx.doi. org/10.1016/j.desal.2009.09.116

SØRHAUG, T.; STEPANIAK, L. Psychrotrophs and their enzymes in milk and dairy products: quality aspects. Trends in Food
Science e Technology, Cambridge, v. 8, n. 2, p. 35-40, 1997. http://dx.doi.org/10.1016/S0924-2244(97)01006-6

TE GIFFEL, M. C.; VAN DER HORST, H. C. Comparison between bactofugation and microfiltration regarding efficiency of somatic cell and bacteria removal. Bulletin of International Dairy Federation, Brussels, v. 389, p. 49-53, 2004.

TOMASULA, P. M.; MUKHOPADHYAY, S.; DATTA, N.; PORTOFETT, A.; CALL, J. E.; LUCHANSKY, J. B.; RENYE, J.; TUNICK, M. Pilot-scale crossflow-microfiltration and pasteurization to remove spores of Bacillus anthracis (Sterne) from milk. Journal of Dairy Science, Lancaster, v. 94, n. 9, p. 4277-4291, 2011. PMid:21854901. http://dx.doi.org/10.3168/jds.2010-3879

VIANA, P. C. B. Adição de Dióxido de Carbono ao Leite Cru: Efeito Sobre a Qualidade e Vida de Prateleira do Leite UHT. 2010. 94 f. Tese (Doutorado em Tecnologia de Alimentos)Faculdade de Engenharia de Alimentos, Universidade Estadual de Campinas, Campinas, 2010.

WIKING, L.; FROST, M. B.; LARSEN, L. B.; NIELSEN, J. H. Effects of storage conditions on lipolysis, proteolysis and sensory attributes in high quality raw milk. Milchwissenschaft, Germany, v. 57, n. 4, p. 190-194, 2002. 